\title{
Anthropometric profile, body composition and somatotyping of national Iranian cross-country runners
}

\author{
Hamid ARAZI, Bahman MIRZAEI, Hadi NOBARI
}

Department of Exercise Physiology, Faculty of Sport Sciences, University of Guilan, Rasht, Iran.

Address Correspondence to H. Arazi, hamidarazi@yahoo.com

\begin{abstract}
This study was conducted to determine the anthropometric profile of selected national athletes. The purpose of this study was to find out anthropometric measurements, body composition and somatotyping of Iranian cross-country runners. The participants were 9 male national Iranian cross-country runners. The age of athletes was between 20 to 32 years. Cross-country personal best 36min 55s (47s); training volume: 120-180 km.wk; All subjects were assessed for height, weight, breadths, lengths, girths and skinfold thickness. Percentage of body fat was calculated from the sum of 7 measurements of skin-fold thickness. The somatotype and height to weight ratio (HWR) as well as the skin-folds extremity to trunk ratio (E:T) were also calculated. The Mean (SD) of LBM (Lean Body Mass), \%BF (Body Fat), WHR (Waist Hip Ratio), HWR (Height to Weight Ratio), E:T (Extremity/Trunk) skin-fold ratio, SAD (Somatotype Attitudinal Distance) and Manourrier were 60.36 (8.25), 8.07 (1.71) \%, .82 (.06), 44.01 (1.00), .77 (.17), 0.90 (0.33) and 1.10 (.63), respectively. The Mean (SD) endomorph, mesomorph and ectomorph were 1.43 (.43), 4.10 (.56), and 3.63 (.73), respectively. National Iranian cross-country runners seem to have mesomorph and ectomorph are equal (or do not differ by more than one-half unit), and endomorph is smaller. Despite population comparisons would be required to identify any connection between specific anthropometric dimensions, these reference data reported in the present study for useful to practitioners and researchers, carry immense practical application and should be useful for future investigation on endurance runners selection, talent identification in cross-country running and training program development.
\end{abstract}

Keywords: Anthropometry, cross-country, somatotype, runner.

\section{INTRODUCTION}

In the endeavor to achieve excellence in sport, all of the possible concomitants of performance have been subject to scientific research. Modern sport science is characterized by the purposefulness of its endeavor to improve elite athletes and to discover talents as precisely as possible (27).

The World Cross-Country Championships have been held under the auspices of the International Association of Athletics Federations (IAAF) since 1973. Because of its nominal length (12 km) (9), the senior men's race most similar to the track distance of $10,000 \mathrm{~m}$. The former six Olympic 10,000 m races have been won by athletes who were also competitive in the World Cross-Country Championships. For instance, World Record holder and two-time Olympic Champion Kenenisa Bekele won the event on six times (11). And also Hamid Sajadi as the first Asian
Cross-Country Running Champion at 2001 and Iran was $10,000 \mathrm{~m}$ races record.

Elite and world class athletes have different physiques than individuals in the non-athletic population (24). In track and field athletics, several studies have considered anthropometric variables relevant to event participation and body composition of runners has been examined extensively $(6,21)$. However, most studies have been with non-elite and heterogeneous groups of performers. There are many different factors influencing performance in endurance exercise (17). Apart from physiological parameters, several anthropometric parameters show an association with endurance performance such as body mass $(2,26)$, body mass index (BMI), body fat $(1,21)$, length of the upper leg (29), length of limbs (19), body height (2), circumference of thigh (29), total skin-fold thickness (2) and skin-fold thickness of the lower limb $(1,21)$. 
A variety of anthropometric and training characteristics have been identified as predictor variables for race performance in endurance and ultra-endurance athletes (14). It has been well established that specific physical characteristics or anthropometric profiles indicate whether the player would be suitable for the competition at the highest level in a specific sport (18). Endurance runners in the study of Hetland et al. (10) had very low amounts off at in the abdomen and legs, which is associated with training intensity. Best marathon runners are usually short and have low body mass $(1.70 \mathrm{~m}$ and $61 \mathrm{~kg}$ on average, respectively). The low body mass is a consequence of very low body fat percentages (usually lower than $7 \%$, sometimes even under the recommended limits) (32). Lower skin-fold values are associated with running performances up to $10,000 \mathrm{~m}$ $(1,2)$ and skin-fold thicknesses in the lower limb are positively associated with running performances $10,000 \mathrm{~m}(1,2,21)$.

Nevertheless, few studies have investigated the track and field athletes in Islamic Republic of Iran. There is no comprehensive data set on the current anthropometric characteristics of Iranian crosscountry runners. Thus, the present study, the quantification of morphological characteristics of elite athletes can be a key point in relating body structure to sports performance. Knowledge of the pacing profiles used by endurance athletes of different abilities can therefore aid both athletes and coaches in understanding successful pacing profiles.

The aims of this study were: 1) to describe the current anthropometric profiles of Iranian crosscountry runners and 2) to establish a set of reference values useful for future investigations on athlete selection, talent identification, and training program development.

\section{MATERIALS \& METHODS}

\section{Design and protocol}

The purpose of this study was to determine the anthropometric characteristics of top-class Iranian cross-country runners and was designed as observational research in describing pacing profiles.

This by means of the measurement anthropometric variables, body height and body mass, lengths $(\mathrm{cm})$, arm span, arm, forearm, hand, thigh, lower leg, foot, breadths $(\mathrm{cm})$; biacromial, transverse chest, anterior -posterior chest, humorous, femur, biilocristal; girths $(\mathrm{cm})$, relaxed arm, flexed arm, forearm, wrist, chest, waist, hip, upper thigh, mid-thigh, calf, ankle. Skin-folds of the seven sites were chest, axilla, triceps, subscapular, abdomen, suprailium, front thigh and relative fat patterning, which refers to the distribution of subcutaneous skinfolds on the body/extremity [(triceps, front thigh, medial calf)/trunk (subscapular, iliac crest, abdominal)] ratio. Body composition (percentage of lean body mass and body fat), of the athletes was assessed by the skin-fold method (Jackson \& Pollock (13)), body mass index and body somatotype, SAD (Somatotype Attitudinal Distance), the threedimensional distance from a profile to the mean of all profiles, height to weight ratio (HWR), according to Carter and Heath (7); were calculated from anthropometric measures.

\section{Participants}

The sample consisted (nine male runners) averaged 25.44 years of age with a standard deviation of 4.15 years. All runners had been training for more than 6 years and had taken part in national or international competition. All measurements on Participants were performed during the tapered stages for the World Military cross-country championships, the Conseil International du Sport Militaire (CISM). During the course of the year, the amount of training sessions range from about 11 sessions and $145 \mathrm{~km}$ during maximum build up phases to about 7 sessions and $70 \mathrm{~km}$ during midcompetition season.

\section{Data Collection}

Anthropometric variables of the subjects were measured using the techniques provided by the International Society for the Advancement of Kinanthropometry (ISAK) and in a resting state (22). These measurements were carried out by one trained investigators using standardized procedures. The person responsible for assessment had 3 years experience in this type of procedure. Informed consents were obtained prior to data collection. Instruments were calibrated prior to use and all variables except body mass and height measurements were taken on the subject's right side. Every measurement was taken three times by the same person, and the mean value was used for calculation. 
Table 1. Absolute size characteristics for national Iranian cross-country runners.

\begin{tabular}{|c|c|c|c|c|}
\hline Variable & Mean & Std. Deviation & Maximum & Minimum \\
\hline Age (years) & 25.44 & 4.15 & 32 & 20 \\
\hline Weight (kg) & 63.55 & 8.71 & 80 & 52 \\
\hline Height $(\mathrm{cm})$ & 175.22 & 7.20 & 190 & 168 \\
\hline $\mathrm{BMI}^{*}\left(\mathrm{~kg} / \mathrm{cm}^{2}\right)$ & 20.63 & 1.57 & 22.50 & 18 \\
\hline Sitting height $(\mathrm{cm})$ & 86.38 & 5.40 & 96.50 & 78.50 \\
\hline Personal best record (min. s) & 36.55 & .47 & 37.21 & 36.05 \\
\hline \multicolumn{5}{|l|}{ Skin-fold (mm) } \\
\hline Chest & 3.66 & 1.22 & 6 & 2 \\
\hline Axilla & 4.66 & 1.22 & 7 & 3 \\
\hline Triceps & 4.33 & 1.22 & 6 & 3 \\
\hline Subscapular & 8.44 & 1.33 & 10 & 7 \\
\hline Abdomen & 7 & 3.04 & 12 & 4 \\
\hline Suprailium & 5.55 & 2.06 & 10 & 3 \\
\hline Front thigh & 7.11 & 1.69 & 9 & 5 \\
\hline Sum of 7 skin-fold (mm) & 40.78 & 8.50 & 56 & 29 \\
\hline Body density & 1.08 & .004 & 1.09 & 1.08 \\
\hline Body fat (\%) & 8.07 & 1.71 & 8.94 & 5.06 \\
\hline Lean body mass (kg) & 60.36 & 8.25 & 76.20 & 50.60 \\
\hline Body fat (kg) & 3.20 & 1.02 & 4.50 & 1.40 \\
\hline $\mathrm{E}: \mathrm{T}^{*}$ skin-fold ratio & .77 & .17 & 1 & .52 \\
\hline \multicolumn{5}{|l|}{ Lengths $(\mathrm{cm})$} \\
\hline Thigh & 46.55 & 1.66 & 44 & 49 \\
\hline Calf & 48.44 & 2.18 & 53 & 46 \\
\hline Arm span & 179.88 & 10.64 & 207 & 172 \\
\hline Forearm & 25.83 & 1.45 & 28 & 23.50 \\
\hline Hand foot & 18.50 & 1.11 & 21 & 17 \\
\hline Arm & 29.33 & 2.23 & 33 & 27 \\
\hline Leg foot & 29.38 & 1.57 & 32 & 27 \\
\hline \multicolumn{5}{|l|}{ Breadths $(\mathrm{cm})$} \\
\hline Biocrominal & 47 & 2.69 & 51 & 43 \\
\hline Transverse chest & 31.27 & 2.03 & 28.50 & 34.50 \\
\hline Ant-post chest & 22.02 & 1.71 & 20 & 24 \\
\hline Humerus & 6.53 & .23 & 6.80 & 6.10 \\
\hline Femur & 10.01 & .85 & 11 & 8.80 \\
\hline Biilocristal & 31.44 & 1.86 & 34 & 28 \\
\hline \multicolumn{5}{|l|}{ Girths (cm) } \\
\hline Relaxed arm & 25.57 & .80 & 27 & 24.40 \\
\hline Flexed arm & 27.87 & 1.22 & 30 & 26 \\
\hline Wrist & 16.13 & 1.03 & 18 & 14.30 \\
\hline Forearm & 25.18 & 1.21 & 26.80 & 23.30 \\
\hline Chest & 90.91 & 5.95 & 85 & 97.15 \\
\hline Waist & 73.98 & 4.61 & 80 & 66.20 \\
\hline Hip & 89.74 & 3.78 & 85 & 94.40 \\
\hline Upper thigh & 52.97 & 3.15 & 56 & 46 \\
\hline Mid-thigh & 49.45 & 3.36 & 53 & 45 \\
\hline Calf & 35.93 & 2.28 & 39 & 32.40 \\
\hline Knee & 35.61 & 1.92 & 40 & 33.30 \\
\hline Abdominal & 75.96 & 5.17 & 82 & 65 \\
\hline Shoulders & 103.55 & 5.45 & 111 & 96 \\
\hline Ankle & 21.68 & 1.10 & 23 & 20.40 \\
\hline $\mathrm{WHR}^{*}(\mathrm{~cm})$ & .82 & .06 & .93 & .73 \\
\hline HWR $^{*}$ & 2.79 & .28 & 3.27 & 2.37 \\
\hline Manouvrier & 1.10 & .63 & 1.19 & 1.01 \\
\hline
\end{tabular}

The technical error of measurement, inter- and intraobserver, was lower than 5\% for skin-folds and lower than $2 \%$ for the other variables. All anthropometric measurements were taken in the morning (08:00-11:00 hours).
Weight was measured to the nearest $0.1 \mathrm{~kg}$ in light clothes without footwear using a digital scale (Seca, Birmingham, UK). Height was measured with as stadiometer to the nearest $1 \mathrm{~mm}$. Widths and diameters of body parts were measured by using sliding caliper. Circumferences were measured with a non-elastic tape to the nearest $1 \mathrm{~mm}$. lengths were 
taken with the steel tape to the nearest $0.5 \mathrm{~cm}$. Skinfold thickness measurements were taken with a Lafayette caliper (Lafayette Instrument Company, Lafayette, IN, USA). Body density (BD) was estimated using the method of Jackson and Pollock (13). BD was transformed to \%BF by the Brozek's equation (4). Height-adjusted endomorph values were used and the somatotypes were plotted on a two-dimensional grid system somatochart using the appropriate software (Somatotype 1.2 software).

\section{Statistical analysis}

All other variables fitted to a normal distribution. Mean, standard deviation, maximum and minimum values are presented.

\section{RESULTS}

The means, standard deviations, maximum and minimum for age, physique, anthropometric variables and body composition are presented in table 1 . The ages of the Cross-country runners in this study varies from 20 to 32 years. The mean body weight of crosscountry runners was $63.55 \pm 8.71 \mathrm{~kg}$. The mean height of cross-country runners was $175.22 \pm 7.20 \mathrm{~m}$. The average percentage of body fat for the cross-country runners was $5.16 \pm 1.54 \%$. The somatotype of runners is also presented in table 2 and the individual somatotype ratings are plotted in Form. 1.

\section{DISCUSSION}

The anthropometric profile of an athlete plays a role in determining his or her potential for success within a sport (30). Specific physical characteristics or anthropometric profiles are required for the highest level of performance in a specific sport (18). In this investigation, anthropometry and body composition data of national Iranian cross-country, including 9 runners were studied, with their performance times in $12 \mathrm{~km}$ races. One goal of sports sciences is to predict exercise performance by laboratory measurements. Anthropometric properties can be divided into two groups. The first, such as body height and the length of the limbs, cannot be associated with the subjects, whereas the second group of anthropometric properties can be the latter group includes body weight, skin-fold thicknesses and limb circumference, which may be altered by specific diets and training (17).
Table 2. Somatotype variables for national Iranian cross-country runners.

\begin{tabular}{lcccc} 
Variable & Mean & SD & Maximum & Minimum \\
\hline Endomorph & 1.43 & 0.43 & 2.1 & 0.8 \\
Mesomorph & 4.10 & 0.56 & 4.9 & 3.1 \\
Ectomorph & 3.63 & 0.73 & 4.8 & 2.7 \\
SAD $^{*}$ & 0.90 & 0.33 & 1.57 & 0.48 \\
HWR $^{*}$ & 44.01 & 1.00 & 45.55 & 42.67 \\
& & & & \\
\hline
\end{tabular}

* SAD (Somatotype Attitudinal Distance); HWR (Height to Weight Ratio).

It has been found that the athletes with lower body fat percentage had higher maximum oxygen uptake ( $\mathrm{VO}_{2}$ max). In other words, the athletes with lower body fat percentage seemed to utilize oxygen most efficiently (12). Arrese \& Ostariz (1) showed in male runners, a high correlation between the thigh and calf skin-folds and $1500 \mathrm{~m}$ as well as $10,000 \mathrm{~m}$ race times. The abdominal and suprailiac skin-fold thicknesses were related to race time in runners such as female and male half-marathoners, male marathoners (16). The sum of skin-folds was related to race performance in runners such as male $10,000 \mathrm{~m}$ runners, female and male $(2,8)$. However, according to Norton et al. in order to avoid the errors and assumptions which could be associated with the use of generalized predictive equations of fat percentage, the sum of skin-fold values from the seven measured sites is recommended as the standard by several authors (23). It would appear that taking into account only the sum of seven skin-folds can provide a general assessment of the athlete. Correspondingly, in this study we determined a low sum of seven skinfolds. In the study of Hetland et al. (10) found that elite long-distance runners had very low amounts of fat in the abdomen, arms and legs, and reduced adipose subcutaneous tissue in the legs was associated with the weekly distance run. During longduration performance, fat seems to be reduced and skeletal muscle mass remains stable. Differences are obvious in skin-fold values among runners competing in classical distances ranging from $100 \mathrm{~m}$ to $10,000 \mathrm{~m}$ (20). Furthermore, Bale et al found that total skinfolds, among other variables such as type and frequency of training and the number of years of running, were the best predictors of running performance and success over $10,000 \mathrm{~m}$ (2). This is probably due to the fact that these runners undertake a higher training volume and that in this vent fat metabolism prevails in training and competition (21). The values of body fat percentage and the sum of all 
skin-folds indicate that runners, regardless the event, have prominently less body fat compared to other athletes of most sport disciplines (31). Minimum level of fatness is particularly advantageous for gymnasts, figure skaters, wrestlers, distance runners and other endurance athletes (12).

Body mass is an easy-to-determine variable for anthropometry. In addition to body mass, body height is also an easy-to-determine variable for anthropometry (14). The general anthropometric data of runners to the values reported by Burke \& Brush (5) for the 1975 and 1976 AAU National Junior CrossCountry Championship teams. The mean height and weight of those runners $\mathrm{x}=16.2 \mathrm{yrs}$ ) were $162.2 \mathrm{~cm}$ and $48.6 \mathrm{~kg}$, respectively, compared to the $175.2 \mathrm{~cm}$ and $63.5 \mathrm{~kg}$, respectively, in the present study. Body height seems to be associated with performances in $10-\mathrm{km}$ running (2). Black runners tend to be smaller and lighter than white runners (17), although these results could not be confirmed in the study of Rahmani et al. (25). However, in contrast to the other studies, found a large span in height in runners, that ranged from $1.57 \mathrm{~m}$ to more than $1.90 \mathrm{~m}$, and concluded (32). Body composition greatly affects the energy-related physical strength and skill in various sports (18).

With the determination of body mass and body height, the variable body mass index using the equation body mass $(\mathrm{kg})$ divided by body height $(\mathrm{m} 2)$ can be calculated (14). In other studies, body mass seems to have a marked effect on endurance performance (17). The effects of body mass and BMI on performance have been investigated in several studies. The BMI of Kenyan runners is $19.2 \mathrm{~kg} / \mathrm{m} 2$ compared with $20.6 \mathrm{~kg} / \mathrm{m} 2$ for the best Scandinavian runners $(16,30)$.

Other factors have also been discussed for runners. In long distance runners, length of the upper leg and thigh girth are related to performance (29), in cross-country runners, seem to be more anthropometric measures in the prediction of performance. Also the length of limbs has been reported as an important predictor variable for endurance performance (14).

A further anthropometric characteristic related to endurance performance is the circumference of limbs of the upper arm, the thigh and the calf $(15,17,29)$.

An important observation from the study is the apparent divergent association between trunk and extremity skin-folds (E:T) with running performance (1). Furthermore, fat patterning refers to the relative distribution of subcutaneous fat on the body as opposed to absolute amounts of fat (30). To examine differences in fat patterning, most researchers compare skin-fold thicknesses on the trunk and extremities. In the present study, the mean E:T is .77 whereas, Kenyan marathon runners were found to have the mean .38 indicating that Kenyan marathon runners seem to have a greater centralization of subcutaneous adipose tissue (30). High correlations were found between the extremity/trunk fat ratio and $400 \mathrm{~m}$ and $1500 \mathrm{~m}$ race time $\left(\mathrm{r}^{1 / 40} / 4.69, \mathrm{P}^{1} / 40.028\right)$, $\left(\mathrm{r}^{1} / 40.77, \mathrm{P} 1 / 40.016\right)$ respectively (1).

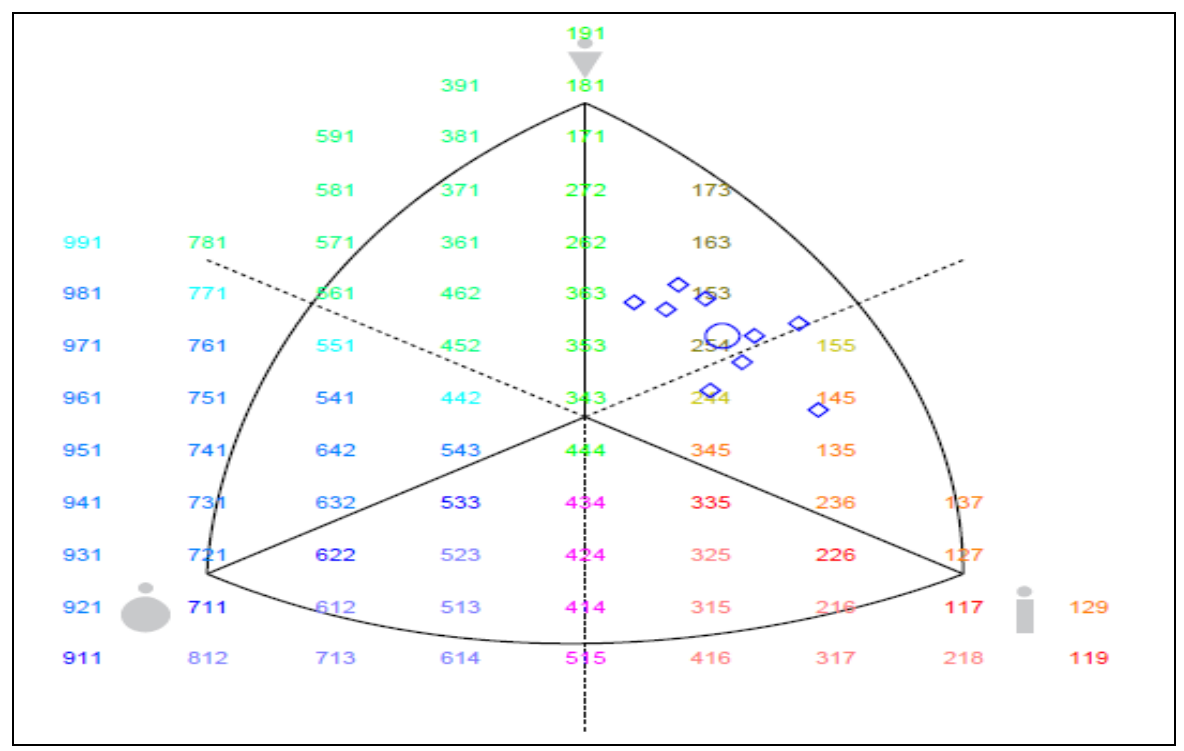

Figure 1. Individual somatotypes national Iranian cross-country runners. $\mathrm{O}=$ mean somatotype (1.4- 4.1-3.6). 
Bale et al. (3) found in their study with female long-distance runners that a slim physique high in ectomorph is associated with improved performance. Whilst the elite and good runners were found exclusively in the ecto-mesomorph and mesoectomorph sectors of the somatochart the average runners had a wider distribution and were found mainly in the end monomorphic sector (2). Three studies do give values for $5000 \mathrm{~m}$ cross-country runners. The reported somatotypes average 2.6, 3.3 and 3.6 for endomorph, mesomorph and ectomorph respectively and show these runners to have lower endomorphic and higher ectomorph (3). The somatotype scores of mean performer cross-country runners are 1.4-4.1-3.6 which accords with the somatotyping scores of the 1984 Olympics participants, long-distance runners 1.4-4.2-3.7 (numbers presented in order as in the Heath-Carter method (6): endomorphic-monomorphic-ectomorph component). The cross-country runners in the present study are mesomorph ectomorph.

The finding of the study will help to understand the anthropometric characteristics and body composition and somatotyping of cross-country runners and coaches can adjust the training programme for cross-country runners with the help of the data regarding body composition. Although the share of particular energy sources varies indifferent proportion from event to event the shorter the track, the more dominant is the anaerobic energy supply and vice versa in endurance events it is mostly aerobic. So, the anthropometric dimensions they have a tendency towards greater mesomorph, moderate height, low body mass index and low percentage body fat. This is information useful in practical application and will be profitable in future investigation on endurance runners selection, talent identification in cross-country runner and training program development.

\section{ACKNOWLEDGEMENTS}

The authors wish to thank the gratitude is extended to the Amateur Athletics Federation of Islamic Republic of Iran and national cross-country runners for their cooperation in this study.

\section{REFERENCES}

1. Arrese AL, Ostáriz ES. Skin-fold thicknesses associated with distance running performance in highly trained runners. Journal of Sports Sciences, 2006; 24(1): 69-76.
Arazi et al. 2015

2. Bale P, Bradbury D, Colley E. Anthropometric and training variables related to $10 \mathrm{~km}$ running performance. British Journal of Sports Medicine, 1986; 20(4): 170-173.

3. Bale P, Rowell S, Colley E. Anthropometric and training characteristics of female marathon runners as determinants of distance running performance. Journal of sports sciences, 1985; 3(2):115-126.

4. Brozek J, Grande F, Anderson JT, Keys A. Densitometric analysis of body composition: Revision of some quantitative assumptions. Annals of the New York Academy of Sciences, 1963; 110: 113-140.

5. Butts NK. Physiological profiles of high school female crosscountry runners. Research quarterly for exercise and sport, 1982; 53(1): 8-14.

6. Carter JEL, Yuhasz MS. Skinfolds and body composition of Olympic athletes. Physical structure of Olympic athletes, Part II: Kinanthropometry of Olympic athletes, 1984.

7. Carter JL, Heath BH. Somatotyping: development and applications (Vol. 5). Cambridge University Press, 1990.

8. Esteve-Lanao J, San Juan AF, Earnest CP, Foster C, Lucia A. How do endurance runners actually train? Relationship with competition performance. Med Sci Sports Exerc, 2005; 37(3): 496-504.

9. Hanley B. Senior men's pacing profiles at the IAAF World Cross Country Championships. Journal of sports sciences, 2014; 32(11): 1060-1065.

10. Hetland ML, Haarbo J, Christiansen C. Regional body composition determined by dual-energy x-ray absorptiometry. Relation to Training, Sex Hormones, and serum lipids in male long-distance runners. Scandinavian Journal of Medicine \& Science in Sports, 1998; 8(2): 102-108.

11. IAAF. Competition archive. 2013b. Retrieved from http://www.iaaf.org/results?\&subcats= WXC

12. Ismail $\mathrm{MN}$, Zawiak $\mathrm{H}$. Anthropometric measurements and body composition of selected national athletes. Malaysian Journal of Nutrition, 1996; 2(2): 138-147.

13. Jackson AS, Pollock ML. Generalized equations for predicting body density of men. British Journal of Nutrition, 1978; 40(03): 497-504.

14. Knechtle B. Relationship of anthropometric and training characteristics with race performance in endurance and ultraendurance athletes. Asian Journal of Sports Medicine, 2014; 5(2): 73-90.

15. Knechtle B, Baumgartner S, Knechtle P, Rüst CA, Rosemann T, Bescós R. Changes in single skin-fold thickness in $100 \mathrm{~km}$ ultramarathoners. Open Access Journal of Sports Medicine, 2012; 3: 147.

16. Knechtle B, Knechtle P, Andonie JL, Kohler G. Influence of anthropometry on race performance in extreme endurance triathletes: World Challenge Deca Iron Triathlon 2006. British Journal of Sports Medicine, 2007; 41(10): 644-648.

17. Knechtle B, Knechtle P, Schulze I, Kohler G. Upper arm circumference is associated with race performance in ultra- 
endurance runners. British Journal of Sports Medicine, 2008; 42(4): 295-299.

18. 18- Koley S, Singh J, Sandhu JS. Anthropometric and physiological characteristics on Indian inter-university volleyball players. Journal of Human Sport and Exercise, 2010; 398-399.

19. Landers GJ, Blanksby BA, Ackland TR, Smith D. Morphology and performance of world championship triathletes. Annals of Human Biology, 2000; 27(4): 387-400.

20. Legaz AA, González BJ, Serrano OE. Differences in skin-fold thicknesses and fat distribution among top-class runners. The Journal of Sports Medicine and Physical Fitness, 2005; 45(4): 512-517.

21. Legaz A, Eston R. Changes in performance, skin-fold thicknesses, and fat patterning after three years of intense athletic conditioning in high level runners. British Journal of Sports Medicine, 2005; 39(11): 851-856.

22. Norton KI, Marfell-Jones M, Whittingham N, Kerr D, Carter L, Saddington K, Gore CJ. Anthropometric assessment protocols. 2000.

23. Norton K, Whittingham N, Carter L, Kerr D, Gore C, MarfellJones $\mathrm{M}$. Measurement techniques in anthropometry. Anthropometrica, 1996; 1: 25-75.

24. Tanner JM. The Physique of the Olympic Athlete. Rome, George Allen and Unwin Limited, 1964.

25. Rahmani A, Locatelli E, Lacour JR. Differences in morphology and force/velocity relationship between Senegalese and Italian sprinters. European Journal of Applied Physiology, 2004; 91(4): 399-405.

26. Sharwood K, Collins M, Goedecke J, Wilson G, Noakes T. Weight changes, sodium levels, and performance in the South African Ironman Triathlon. Clinical Journal of Sport Medicine, 2002; 12(6): 391-399.

27. Singh S, Singh K, Singh M, Singh M. Measurements, body and somatotyping of high jumpers. Brazilian Journal of Biomotricity, 2010; 4(4): 266-271.

28. Stuelcken M, Pyne D, Sinclair P. Anthropometric characteristics of elite cricket fast bowlers. Journal of sports sciences, 2007; 25(14): 1587-1597.

29. Tanaka K, Matsuura Y. A multivariate analysis of the role of certain anthropometric and physiological attributes in distance running. Annals of Human Biology, 1982; 9(5): 473-482.

30. Vernillo G, Schena F, Berardelli C, Rosa G, Galvani C, Maggioni M, Agnello L, La Torre A. Anthropometric characteristics of top-class Kenyan marathon runners. The Journal of Sports Medicine and Physical Fitness, 2013; 53(4): 403-408.

31. Vučetić V, Babić V, Šentija D, Nekić B. Anthropometric and morphological characteristics of runners. Zbornik Radova, 2005; 4: 612-615.

32. Vučetić VR, Matković B, Šentija D. Morphological differences of elite Croatian track-and-field athletes. Collegium Antropologicum, 2008; 32(3): 863-868. 